\title{
O ginecologista e a sexualidade masculina
}

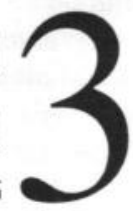

Nelson Vitiello*

\section{A NECESSIDADE DO CONHECIMENTO}

Vivemos um período muito peculiar na história da humanidade. Nunca, em todos os milênios sobre os quais temos notícias, foram rediscutidos e revistos os conceitos vigentes tais como tem sido na atualidade. A acentuada urbanização, as mudanças conceituais dos papéis, a extensiva e intensiva utilização da tecnologia são marcas salientes de nossa vida no limiar deste novo século, num nível nunca dantes experimentado.

Aliando-se a esses fatores, o elevado grau de eficácia e a grande penetração alcançada pelos meios de comunicação de massa, notadamente a televisão, a internet e os meios impressos tem sido um fator importantíssimo na formação de novos conceitos, hábitos e costumes de nossa sociedade. Claro que desde as pinturas rupestres das cavernas neolíticas sempre existiram meios de influenciar as pessoas. Entretanto, foi com a vulgarização da televisão, a popularização da informática e o aprimoramento dos recursos gráficos que esses meios se tornaram mais eficientes, ganhando cada vez maior relevância em nossas vidas.

* Ginecologista e Terapeuta Sexual. Doutor em Medicina pela USP. Presidente da Sociedade Brasileira de Estudos em Sexualidade Humana (SBRASH).

Recebido em 07.11 .00

Aprovado em 29.11.00 
No que diz respeito às condições de exercício da sexualidade, os meios de comunicação tem representado importante papel. Em programas de televisão, nas revistas femininas e em outros meios, a sexualidade tem sido discutida e apresentada com diferentes graus de coerência e sensatez. Esse fato se tornou comum nas últimas décadas, em especial após o surgimento da AIDS e a liberação de costumes, sendo cada vez mais necessário que se fale em sexualidade e nos problemas advindos das disfunções sexuais.

De maneira geral, embora existam exceções, na maioria das vezes os meios de comunicação tem apresentado uma imagem muito distorcida da sexualidade, levando a crer ser o orgasmo a meta suprema da vida. Nessa perspectiva, todos os outros aspectos do relacionamento humano ficam prejudicados frente a "desgraça" que é para a mulher não conseguir ser multiorgásmica.

Nesse contexto, ainda imbuído de um multimilenar machismo, os homens tem-se sentido acuados, com dificuldades de conviver com a "nova" mulher que está eclodindo desse processo. Associa-se a isso o sentimento masculino de responsabilidade pelos orgasmos femininos ou, o que é ainda pior, pela falta desses orgasmos.

É inegável, no entanto, que a divulgação das possibilidades prazerosas do exercício da sexualidade trouxe consigo a maior possibilidade de que se repensem valores e discutam desempenhos, o que tem facilitado o surgimento de queixas sobre o desempenho sexual. Deve ser realçado que, na opinião da maioria dos especialistas, não tem ocorrido um real aumento do número de pessoas sexualmente disfuncionais, mas sim que esses homens e mulheres tem-se sentido mais encorajados a se queixar de tais problemas.

Já não é tão incomum quanto outrora que pacientes explicitem queixas referentes ao desempenho sexual, embora ainda muito freqüentemente essas queixas venham disfarçadas no meio de outras, e raramente constituam o motivo declarado da consulta. Mesmo assim, entretanto, tem elas se tornado mais evidentes. Em trabalho de nossa co-autoria, publicado em 1972 - já lá se vão quase trinta anos, encontramos que $60 \%$ das pacientes de um ambulatório de ginecologia apresentavam alterações de desempenho sexual, embora em apenas $2 \%$ das vezes a consulta tivesse essa disfunção como motivação primeira. Sem dúvida, se hoje repetíssemos essa mesma pesquisa o número de consultas explicitamente motivadas por problemas ligados à sexualidade seria maior; duvidamos, entretanto, que representasse a totalidade dos casos, sendo ainda muitas das queixas disfarçadas entre as de um corrimento ou de uma dispareunia. É comum, por exemplo, que a mulher adie a formulação de sua queixa sexual durante todo o decorrer da consulta, deixando para fazê-la quase que no momento de despedir se. Tem-se a impressão que a paciente vai postergando a apresentação do real problema que a levou à procurar o médico, enquanto toma coragem para fazê-lo. Outras vezes, uma excessiva preocupação sobre a possível origem de um corri- 
mento pode disfarçar o temor de ser ele de transmissão sexual e ocultar a culpa por uma relação extraconjugal, ou o receio de ter que admitir uma infidelidade praticada pelo marido.

O que se pode concluir é que sem dúvida está ocorrendo na atualidade um momento de "liberação" dos costumes sexuais, embora a maioria das pessoas ainda seja liberal apenas no discurso. Esse fato tornou menos penoso, senão mais fácil, às pacientes a exposição de suas dificuldades diante de manifestações da sexualidade.

De qualquer maneira, porém, é importante que os ginecologistas se preparem para $o$ atendimento das queixas sobre as dificuldades sexuais do casal, pois explicitadas ou não essas disfunções existem, são freqüentes e relevantes. Isso se faz necessário porque é sem dúvida ao ginecologista que a maioria das mulheres e talvez até a maioria dos casais faz chegar suas dúvidas e queixas a respeito da sexualidade como um todo e do desempenho sexual em particular.

Sendo o ginecologista o especialista que mais de perto lida com aspectos da reprodução, parece normal que a ele também se reportem os fatos $\mathrm{e}$ as fantasias ligadas à sexualidade. $\mathrm{O}$ fato de desnudar-se fisicamente para o exame ginecológico, a necessidade de contar fatos ligados a processos emocionais tão íntimos que não são comumente relatados sequer a grandes amigos, faz com que a paciente veja no ginecologista o natural e fiel depositário de dúvidas e confidências. Mais ainda, com praticamente total extinção da antiga figura do "médico de família", os ginecólogos são freqüentemente chamados para exercitar, ao menos em parte, aquelas funções de amigo confiável, conselheiro ponderado e profissional capaz, que aquele clínico outrora exercia. Nada mais natural, segundo a óptica de nossas pacientes, que as dúvidas e queixas de âmbito sexual e até mesmo a aspectos problemáticos da educação sexual dos filhos acabem chegando ao ginecologista.

Acresce a esses fatos a alta freqüência com que, por preconceitos machistas ou por desinformação, são trazidas também a nós as queixas sobre o desempenho sexual dos maridos, visto que estes raramente procuram espontaneamente psicoterapeutas, urologistas ou andrologistas.

Ocorre, entretanto que a imensa maioria dos cursos de medicina existentes no país não prepara seus educandos para exercer essas funções. Nós, médicos, somos, habitualmente, adestrados a fundo para conhecer sutis aspectos da reprodução, aprendemos fantásticos detalhes sobre metabolismo íntimo dos gametas, sendo nos ensinado, pormenorizadamente, os complexos movimentos tubários. No entanto, nada aprendemos sobre como aquele espermatozóide em especial foi parar naquela trompa em particular. Em outras palavras, não consta do currículo da maioria - senão da totalidade - das escolas de medicina qualquer instrução a respeito de desejo, padrões de conduta sexual ou mesmo informações sobre a fisiologia da resposta sexual humana. Essa falha, que não é sanada sequer na Residência Médica, faz com 
que nós médicos ginecologistas saibamos sobre sexo o que qualquer adulto medianamente instruído em outro ramo profissional sabe; a diferença é que somos chamados, profissionalmente, a atuar nessa área.

$\mathrm{O}$ despreparo dos médicos, considerando-se apenas o que as Faculdades de Medicina ensinam, que nem mesmo sua própria sexualidade é melhor resolvida do que a dos pacientes. Portamos as mesmas limitações, os mesmos preconceitos machistas e as mesmas sensações de culpa para lidar com o tema que os leigos ou profissionais de outras áreas.

Dentro do esquema social machista em que nossa cultura está imersa, os médicos portam os mesmos preconceitos que sua clientela. Por isso, não é raro que sejamos presa fácil de sentimentos conflitantes, pela peculiar situação profissional em que nos encontramos, ao nos tornarmos depositários de confidências íntimas. Assim, frente a expectativa de que sua atuação resolva os problemas emergentes, é comum que o profissional, acuado pela situação, expresse o que não devia, recomende o que não poderia e assuma condutas inadequadas.

$\mathrm{Se}$, como ginecologistas, somos notoriamente despreparados para lidar com as queixas de nossas pacientes, o problema ainda se torna mais grave quando se trata de queixas sobre situações disfuncionais dos maridos. No que diz respeito às disfunções masculinas nossa formação é ainda mais precária, o que faz com que por vezes atuemos baseados muito mais em nossos preconceitos do que em dados cientificamente embasados.

Não estamos preparados para enfrentar situações geradas por disfunções e inadequações masculinas, queixas cada vez mais comuns em consultórios de ginecologistas, visto que a imensa maioria dos homens, ainda levados por preconceitos diversos, recusa-se a procurar diretamente ajuda, solicitando às esposas que peçam ao seu médico indicações milagrosas que possam resolver os problemas.

Outras vezes, disfarçado em problemas sexuais femininos, encontramos subjacente uma disfunção masculina. Não é incomum que maridos portadores de Ejaculação Precoce, por exemplo, convençam suas parceiras de que elas é que tem problemas, demorando demais para chegarem ao orgasmo.

Em diversa mas similar situação, uniões de muitos anos vão deixando de serem prazerosas do ponto de vista sexual, o que faz diminuir o desejo, espaçando os episódios de coito. Essa eventualidade, que pode ocorrer em um ou ambos os membros do casal, pois para homens e mulheres, se a prática da sexualidade não se constituir em experiência atraente há nítida e progressiva perda do desejo. Como nossa cultura - também aqui - penaliza mais a mulher, não é raro que os homens as culpem, alegando estarem gordas, "largas" ou pouco atraentes. Tal posicionamento evidentemente é, em grande número de casos, uma tentativa de disfarçar uma disfunção sexual masculina.

Além dessas situações existem também aquelas em que a disfunção sexual é claramente masculina. Também nessas situações quase sempre é o 
ginecologista o primeiro profissional a ser procurado. Descrições de diminuição ou abolição do desejo, de perda da capacidade ejaculatória ou - o que é mais comum - uma disfunção erétil chegam freqüentemente aos ginecologistas, através de relatos das mulheres.

O profissional então se vê na difícil situação de ter que orientar os maridos de suas clientes, através das mesmas, na busca e na correção do fator causal da disfunção masculina. Mas se nem mesmo para atendimento das queixas sexuais femininas estamos preparados, como atuar se a queixa diz respeito a parte masculina?

Defendemos a tese de que todos os médicos, independentemente da especialidade que abraçam, deveriam ser preparados para um atendimento mínimo às queixas sexuais. Aprendizado para saber ouvir, tipificar a queixa, orientar os casais e buscar e tratar eventuais causas orgânicas deveriam, em nossa opinião, fazer parte da formação dos profissionais, constando da grade curricular das Faculdades de Medicina. E se isso é verdade para todos os profissionais da área médica, os especialistas mais diretamente ligados às questões genitais e reprodutivas, como urologistas e ginecologistas, deveriam receber um preparo ainda mais intensivo. $O$ preparo que advogamos como indispensável deveria ir ao menos até o momento de diagnosticar e tratar causas orgânicas, visto que nem todos tem pendores, interesse ou ocasião de se especializarem em técnicas de terapia sexual, para o tratamento das causas psicogênicas.

No entanto, o diagnóstico correto do problema, a sistemática de busca de fatores orgânicos causais e seu tratamento, no que diz respeito aos problemas da sexualidade feminina e masculina é função inalienável e indispensável para os profissionais que militam na área da reprodução. E dentre estes, pelos fatores citados, salta aos olhos a necessidade de preparo dos ginecologistas.

O conceito de saúde esposado pela Organização Mundial da Saúde é o bem estar físico, psicológico e social do ser humano. Dentro desse amplo conceito, a pergunta que fica é: como o ginecologista pode estar cuidando adequadamente da saúde de suas clientes se não se preocupa com seu bem estar sexual, que reflete também a saúde sexual do homem? Afinal, ninguém pode ser sexualmente realizado sozinho e, para isso, nossas pacientes evidentemente devem ter parceiros sexualmente sadios.

Compreenda-se que não estamos advogando a transformação dos ginecologistas em urologistas ou em terapeutas sexuais, mas sim afirmando que, dentro de um contexto mais genérico de saúde, deve ele ter conhecimentos básicos dos mecanismos de fisiologia sexual de ambos os sexos.

Mesmo não se transformando em especialistas, os ginecólogos deveriam trazer conhecimentos que lhes permitissem compreender melhor a sexualidade masculina, para bem orientar e eventualmente tratar os casais sob sua responsabilidade profissional. 
Além das noções básicas sobre a anatomia e fisiologia do aparelho reprodutor masculino, é importante que o ginecologista tenha conhecimento sobre a resposta sexual masculina e suas possíveis disfunções.

Quando se observa a atividade sexual em seus aspectos orgânicos, isto é, no que diz respeito ao cumprimento das fases da resposta sexual, pode-se encontrar situações em que uma ou mais dessas fases não são cumpridas a contento. São as denominadas "Disfunções Sexuais".

Discorreremos brevemente, a seguir, sobre as mais comuns disfunções sexuais registradas entre os homens, bem como as mais comuns e eficientes formas de tratamento.

\section{AS DISFUNÇÕES SEXUAIS MASCULINAS}

Reserva-se o termo Disfunção Sexual para aquelas situações em que os componentes orgânicos da resposta sexual (aqui vista como uma função) apresentam alguma alteração. Essa alteração funcional, por exemplo uma ausência de ereção, pode ter uma causa orgânica ou psicossocial; qualquer que seja a causa entretanto, ela manifesta danos ao componente orgânico da resposta, isto é, à sexualidade vista como uma função. Podemos então afirmar que a Disfunção Sexual é um "bloqueio", total ou parcial, da resposta sexual normal.

Ainda sobre os fatores causais, é importante reconhecer serem eles dificilmente dissociáveis. Mesmo quando primariamente pode ela ser identificada como orgânica, por exemplo, podem surgir fatores psicológicos que a amplifiquem. Apenas para dar uma idéia da complexidade do problema, citemos o caso de uma banal doença de pele, que a primeira vista não pode ter qualquer repercussão sobre a sexualidade do indivíduo; se essa moléstia entretanto fizer com que ele seja considerado "repelente", sem dúvida ele poderá desenvolver uma disfunção psicogênica, a partir dessa causa orgânica. Outras vezes uma depressão emocional pode levar o indivíduo ao uso de alguns tranqüilizantes que bloqueiem a resposta sexual; assim, uma causa primariamente psicológica acaba desencadeando, por via orgânica, uma disfunção sexual.

Como já vimos, a resposta sexual é usualmente dividida em fases, com a finalidade de facilitar seu estudo. Então, conforme a fase de resposta em que esse bloqueio se manifeste, podemos ter uma "Disfunção de Desejo", "Disfunção de Excitabilidade", ou "Disfunção do Orgasmo". A quarta fase da resposta, denominada de "Fase de Resolução", por não ter sua existência bem caracterizada em ambos os sexos e por não envolver propriamente características orgânicas de atividade, não apresenta disfunções identificáveis.

Citaremos as principais dessas disfunções, distribuindo-as nas fases em que surgem. 


\section{I - Disfunções do Desejo}

Podem incidir em ambos os sexos, sendo denominadas habitualmente de "Inapetência Sexual", quando ocorre diminuição ou ausência de desejo, e "Erotomania", quando ocorre excesso de desejo. Nessa última situação, mais comumente fala-se em "Satirismo" (para homens) ou "Ninfomania" (para mulheres).

Como já frisamos, a resposta sexual apresenta características muito variáveis de pessoa para pessoa, ficando muito difícil conceituar o que seria "normal", em matéria de freqüência de desejo. Deve-se ter muito cuidado ao se tentar definir o que é "normal" em sexualidade, sob pena de passarmos conceitos inverídicos e potencialmente prejudiciais; entretanto, pode-se a grosso modo considerar como "normal" o surgimento de impulsos sexuais desde diários até quinzenais, na dependência da disponibilidade de parceiras interessantes e interessadas, tipo de atividade, faixa etária, e outras variáveis. Importa ainda considerar situações em que o desejo existe, mas faltam condições sociais ou psicológicas para que ele se expresse diretamente em atividades sexuais.

Deve-se aqui fazer uma distinção entre a patologia eminentemente sexual de que estamos tratando e outras perturbações emocionais. É o caso, por exemplo, da denominada "erotofobia" ou "aversão sexual", perturbação de origem fóbica, na qual o portador entra em estado de angústia a simples possibilidade de um relacionamento sexual. Essa patologia foge aos objetivos deste texto, enquadrando-se melhor, como as demais fobias, em textos em que se versem as patologias psiquiátricas.

Além da situação da paixão, um reconhecido afrodisíaco, importa lembrar também que a freqüência de relações tem importante papel na gênese dôo desejo. Em outras palavras, quanto mais assíduos forem os relacionamentos sexuais, mais freqüente será o desejo e vice-versa.

As causas orgânicas mais freqüentes são as anomalias genéticas, as alterações de fundo hormonal (baixa de testosterona ou aumento da prolactina), as doenças agudas e crônicas, os traumas e o uso de drogas causadoras de dependência ou mesmo de alguns medicamentos.

Importa lembrar, quando se pensa em tratamento de tais disfunções, que é comum a associação de causas orgânicas com outras, de fundo psicossocial. Assim, ocorrem com freqüência situações onde uma leve deficiência androgênica, comum em certas fases da vida, associe-se a preconceitos os mais diversos relacionados à incapacidade sexual como conseqüência inevitável da idade.

O tratamento das disfunções de desejo de causa orgânica é, sem sombra de dúvida, a correção desse fator, quando possível. Assim, se a disfunção é gerada por uma baixa androgênica, está indicada a administração de testosterona; se o fator é o uso de determinados fármacos (alguns hipotensores, por exemplo), devem ser eles substituídos. 
Das causas psicossociais citaremos como mais freqüentes a educação sexual inadequada, a repressão sexual, os tabus e crendices, as vivências destrutivas e as relações inadequadas. Quanto a esse último item, talvez uma das causas mais comuns de diminuição do desejo seja a denominada "habituação sexual", na qual o interesse sexual de um casal vai se desgastando por falta de imaginação e por desinteresse mútuo.

$\mathrm{O}$ tratamento de tais causas passa obrigatoriamente por um tratamento psicoterápico, sendo de eleição a terapia sexual.

\section{II - Disfunções da Excitabilidade}

Atingem as manifestações sexuais da excitabilidade, no homem como alterações da ereção, e na mulher como alterações da lubrificação vaginal.

No caso masculino, são genericamente denominadas de "Disfunções da Ereção" ou "Disfunções Eréteis", sendo desejável que se abandone o uso do termo "impotência" pois este, por mais difundido e conhecido que seja, não é suficiente preciso para que se justifique seu uso. A "Disfunção Erétil" é conceituada como sendo a incapacidade persistente, total ou parcial, de iniciar ou manter uma ereção suficiente para efetuar a penetração e a realização do coito até a ejaculação. Como se vê é uma definição ampla, implicando não só na ausência de ereção, mas também na ereção incompleta ou de curta duração. Pode ela ser primária ou secundária, conforme tenha surgido ou não desde o início da atividade sexual; geral ou situacional, segundo sua manifestação seja constante ou apenas em determinadas circunstâncias.

Chamemos a atenção para o fato de que, habitualmente, o homem portador de uma disfunção erétil consegue ter orgasmos, seja por masturbação, coito oral, ou qualquer outro método. Essa advertência é necessária porque a mulher com Disfunção de Excitabilidade não consegue, habitualmente, chegar ao orgasmo, havendo assim uma marcante diferença entre os sexos.

Quanto ao fator causal, pode ser desencadeada tanto por situações orgânicas quanto por psicossociais.

As causas orgânicas são em geral mais comuns em homens mais idosos, embora possam incidir também entre os jovens, podendo ser originárias de doenças agudas ou crônicas, traumas e uso de drogas.

O tratamento dessa disfunção deve obrigatoriamente passar pela correção do fator causal, quando isso for possível. Além disso, se o problema é determinado por pequenas alterações funcionais (tais como discretas insuficiências vasculares), deve-se indicar os facilitadores da ereção, como o Sildenafil, por exemplo.

Os fatores causais psicossociais são os predominantes entre jovens, sendo sempre agravadas pelo acentuado peso que a sociedade confere ao 
desempenho sexual do homem. A angústia de se ver frente a possibilidade de não conseguir uma ereção (o chamado "temor de desempenho") pode, por si só, ocasionar a falta dessa ereção. Devemos lembrar que o pênis é um "cabide" onde se penduram muitas coisas, como a auto-estima, a expectativa de desempenho e a própria qualificação da pessoa enquanto ser humano. Pelo peso emocional que essas coisas tem em nossa cultura, não é de se estranhar que, por vezes, o cabide despenque.

Nessa situação, além da necessária psicoterapia (e aqui voltamos a realçar a importância da Terapia Sexual), há reais benefícios no uso de facilitadores da ereção, visto que em tais situações o simples fato de conseguir uma ereção, ainda que com a ingestão de um fármaco, pode devolver ao homem a auto-confiança necessária para o desempenho sexual.

\section{III - Disfunções do Orgasmo e da Ejaculação}

Contrariando muitas classificações, que consideram a disfunção orgásmica separadamente dos distúrbios da ejaculação, preferimos incluílas num mesmo item, tendo em vista que o comum é que a ejaculação ocorra juntamente com o orgasmo, embora possam ser fenômenos diversos. Assim, dizer que um homem tem "Ejaculação Prematura" equivale, em nosso entender, a dizer que ele é portador de um "Orgasmo Prematuro".

No sexo masculino, o retardo ou a ausência de orgasmos e ejaculações (o denominado "Bloqueio Ejaculatório") são achados raros, representando cerca de $1 \%$ das disfunções relatadas. Se ocasionais, são seguramente conseqüentes à fatores situacionais, e sequer merecem tratamento específico, pois nesses casos o comum é que, desaparecido o fator situacional, a resposta sexual torne-se fisiológica. Se muito freqüentes ou permanentes esses episódios, entretanto, devem ter suas causas (freqüentemente psicossociais) averiguadas e tratadas, visto que a falta da recompensa do prazer orgásmico acaba levando o indivíduo ao desinteresse pela atividade sexual, gerando-se assim uma situação de Disfunção de Desejo.

A Ejaculação Prematura, por outro lado, não tem qualquer interferência quanto à fertilidade do casal, se o homem tem ejaculações intravaginais. Essa disfunção, por isso mesmo, é menos intolerável para os homens do que as Disfunções Eréteis, tendo em vista que socialmente uma esposa grávida é um fato aceito como uma prova de virilidade. Além disso, na ótica machista da busca do prazer apenas para o homem, a Ejaculação Prematura não chega sequer a ser reconhecida como um problema, pois seu portador tem desejo, excitabilidade e orgasmo, ficando assim satisfeito com seu desempenho. Muitas vezes até, como já citamos, está convencido de ser absolutamente normal, não tendo sua parceira orgasmos por problemas sexuais dela própria. 
Convém neste ponto relembrar um item da fisiologia da resposta sexual humana, que diz respeito às diferenças sexuais de tempo e de grau de excitabilidade necessária para o desencadeamento do orgasmo. Por ser a mulher fisiologicamente mais lenta em sua excitação, para a maioria dos casais ocorre o orgasmo masculino antes do feminino, se ambos partem do grau mínimo de excitabilidade. Em alguns casos, o que inicialmente parece ser uma situação de Ejaculação Prematura, nada mais é do que um grave desconhecimento da fisiologia da resposta sexual. Neste caso, a simples orientação do casal, no sentido de só começarem o coito quando a mulher já estiver bastante excitada, resolve o problema, evitando-se uma cara, demorada e inútil terapia.

Para fins práticos, conceitua-se como Ejaculação Prematura aquela que ocorre em prazo de até 30 (trinta) segundos após a penetração. Outros autores preferem tomar como parâmetro, para definição, o número de movimentos intravaginais executados; segundo esse conceito, os ejaculadores prematuros teriam ejaculação com até 15 movimentos coitais. Finalmente, resta registrar a conceituação clínica proposta por Masters e Johnson, segundo a qual ejaculador prematuro seria o homem que não consegue conter a ejaculação até que sua parceira tenha orgasmo, ao menos em 50\% das vezes.

A ejaculação prematura tende a ser progressiva num significativo percentual de casos, isto é, muitos ejaculadores prematuros vão se tornando cada vez mais prematuros. Nas situações mais graves, os indivíduos não conseguem sequer a penetração, ejaculando com a simples proximidade do pênis com a vagina.

Essa situação provoca uma acentuada queda na auto-estima do portador, além de levar a enormes dificuldades de relacionamento do casal, tendo em vista a "cobrança" que a parceira freqüentemente exerce, por sentir-se rejeitada. Do ponto de vista emocional, a insegurança ocasionada pela situação faz com que o homem perca totalmente a espontaneidade, passando a ter relações sexuais não mais para ter ou propiciar prazer, mas sim para testar-se.

$\mathrm{O}$ fator causal mais freqüente é também aqui o psicossocial, como uma conseqüência do aprendizado inadequado em sexualidade.

\section{REFERÊNCIAS BIBLIOGRÁFICAS}

CAVALCANTI, R. e CAVALCANTI, M. Inadequações sexuais. São Paulo: Roca, 1992.

CAVAlCANTI, R. e VITIELLO, N. Sexologia I. 2. ed. São Paulo: CEICH, 1997.

COSTA, M. Sexo: dilema do homem. São Paulo: Gente, 1993. 
FALCONET, G. e LEFAUCHEUR, N. A fabricação de machos. Rio de Janeiro: Zahar, 1997.

LUZ, H. S. O clínico diante da sexualidade. Selecta 9(2):31, 1986.

OLIVEIRA, S. R. C. A sexualidade e o homem. São Paulo: Lemos Editorial, 2000. SAFFIOTI, H. $O$ poder do macho. São Paulo: Moderna, 1988.

SILVEIRA, M. T. O ginecologista e a paciente disfuncional. RBSH 3(1): 23-30, 1992.

VITIELLO, N. Sexualidade: quem educa o educador? São Paulo: Iglu, 1997.

VITIELLO, N. $O$ ginecologista e a sexualidade. In Tratado de Ginecologia, Ed. HW Halbe. São Paulo: Roca, 2000, p. 1897-909.

VITIELLO, N.; CUNHA, A. C. M.; VERRONE, M. e VITIELLO, M. Distúrbios da libido e do orgasmo. GO 6(12):27-32, 1972. 